\title{
Research on one-to-many supply chain with inventory inaccuracy based on RFID technology
}

\author{
Quansheng LEI ${ }^{1, a}$, Xinyi JIANG ${ }^{2, b}$ \\ ${ }^{1}$ Automation School, Beijing University of Posts and Telecommunications, Beijing, 100876, China \\ ${ }^{2}$ Automation School, Beijing University of Posts and Telecommunications, Beijing, 100876, China \\ aemail:leiqshz@163.com, bemail:xiny.xiny@163.com
}

Keywords:RFID technology; inventory inaccuracy; buyback contract; supply chain

\begin{abstract}
Inventory inaccuracy is common in the modern supply chain and it attracts much attention from many researchers. This paper considers a supply chain with inventory shrinkage and misplacement, and the supply chain consists of a single supplier and multiple retailers who are engaged in both price and inventory competition. The buyback contract is attached to coordinate the supply chain, as well as radio frequency identify (RFID) technology is attached to solve the inventory inaccuracy problem. In the first scenario, the supplier only uses the buyback contract to optimize operations by taking into account the inventory inaccuracy that faced by retailers. In the second scenario, the supplier improve operations by adopting RFID technology. Finally, this paper uses numerical example to analyze the difference before and after applying RFID. The consequences extend the study of inventory inaccuracy and highlight the conditions to adopt RFID, which can give helpful insights to supply chain managers.
\end{abstract}

\section{Introduction}

As information technology continues to progress and global trade has become more sophisticated, consumers' demands have become more diverse. In this context, multi-channel distribution is developing. However, there are complex interrelationships among multiple channels, and the increasing number of distribution channels inevitably intensifies the channel competition. At the same time, the discrepancy between inventory records and the amount of product effectively available for sale to customers widely presents in the retail operations, which greatly affects the members' competiveness in channel competition. Hollinger and Adams (2010) reported in the National Retail Security Survey that inventory shrinkage accounts for $1.44 \%$ of total annual sales in USA and retailers lose more than $\$ 33$ billion due to shrinkage in 2009. Raman et al. (2001) claimed that the lost sales due to misplaced products caused the retailer's profits reduced by $25 \%$. Advances in information technology, radio frequency identification (RFID) technology is being discussed as a powerful approach to solve the problem of inventory inaccuracy. Fan et al. (2015) focused on the impact of RFID technology adoption on supply chain decisions with shrinkage and misplacement problems in the Internet of Thing. Rekik et al. (2015) analyzed the impact of inventory inaccuracies on supply chain performance and applied RFID to enable the reduction of the relevant errors.

Our paper mainly refers to Zhao's research published in 2007, i.e. Ref. [5]. The focus of the author is to use the buyback contract to coordinate a supply chain system with retailers under both price and inventory competition. On the results of this, we further consider the situation that retailers face the inventory inaccuracy, which is ubiquitous. We apply the shrinkage and misplacement rate of retailers' inventory to simulate the real situation. Besides this, we propose the using of RFID technology, and we use the tag cost to evaluate the efficiency. On the other hand, our numerical results mainly focus on the effect of inventory inaccuracy on the systems, and how RFID technology can be applied in supply chain.

This paper will investigate the following questions: In order to achieve the best performance of the whole supply chain system, how can a supplier coordinate a multichannel supply chain system with competitive retailers when they face the inventory inaccuracy? When do the supplier benefit from RFID technology? And the paper is organized as follows. In Section 2, we introduce the 
model. In Section 3 we provide numerical results and analysis. In Section 4, we conclude with a discussion of our results and suggestions for future research.

\section{The Model}

Consider a supplier selling to $\mathrm{N}$ oligopoly retailers in a market. Before the selling season, the supplier announces the wholesale price $w_{i}$ and buyback price $b_{i}$ to each retailer $i(i=1 \ldots N)$. These indexes may be different for each retailer because of product characteristics or costs. Products are delivered immediately after being ordered.

Without RFID technology, retailers face the same level of inventory inaccuracy during the selling season, so they can only sell visible parts of products on the shelves, then the demands are satisfied and the profits are collected. At the end of selling season, retailers will find the misplaced products by checking, and the supplier will buy the misplaced products and the excess order quantity with buyback price $b_{i}$. However, with RFID technology, the supplier pays the tag costs for retailers in order to help them reduce the whole unsatisfied demands, and retailers will no longer be troubled with inventory inaccuracy.

\subsection{The General Model without RFID technology}

\subsubsection{The Retail's Problem}

We list some basic parameters at first. $L_{i}(\vec{p})$ is the deterministic demand of retailer $\mathrm{i}$, having $L_{i}^{(i)}(\vec{p})=d L_{i}(\vec{p}) / d p_{i} \leq 0$ and $L_{i}^{(j)}(\vec{p})=d L_{i}(\vec{p}) / d p_{j} \geq 0$, where $\vec{p}=\left(p_{1}, p_{2}, \cdots, p_{N}\right)$. And $\varepsilon_{i}$ is the price-independent uncertain demand of retailer $\mathrm{i}$, having a general probability density function $(P D F) f_{i}($.$) and cumulative distribution function (C D F) F_{i}($.$) . And y_{i}$ is the safety stock of retailer $i$.

Weuse $L_{i}(\vec{p})+D_{i}^{s}$ to model a retail's demand, where $D_{i}^{s}=\varepsilon_{i}+\sum_{j \neq i} \gamma_{j i}\left(\varepsilon_{j}-y_{j}\right)^{+}$having the associated PDF $f_{D_{i}^{s}}$ (.) and the CDF $F_{D_{i}^{s}}($.$) , and \sum_{j \neq i} \gamma_{j i}\left(\varepsilon_{j}-y_{j}\right)^{+}$presents the demand switch from retailer $\mathrm{j}$ because of a stockout or a higher price. Before knowing the demand, retailers need to make decisions on retail prices pi and safety stocks. So the total order of a retailer is $Y_{i}=L_{i}(\vec{p})+y_{i}$.

At the same time, we hypothesize that retailers face the same level of inventory inaccuracy. There are two indicators: $\alpha$ is the rate of shrinkage, $0 \leq \alpha \leq 1$, and $\beta$ is the rate of misplacement, $0 \leq \beta \leq 1$. To simplify the formula, we let $\lambda=1-\alpha-\beta$ to represent the overall inventory inaccuracy. The misplaced inventory can be recovered and be repurchased by the supplier at the end of the selling season. We assume that direct demand can always be satisfied because the uncertain part of it can be made up by safety stock yi. So the inventory can be used to sale is $L_{i}(\vec{p})+\lambda y_{i}$.

So the retailer's problem is to make a decision on $\mathrm{p}_{\mathrm{i}}$ and $\mathrm{y}_{\mathrm{i}}$ to maximize $\pi_{i}^{r}$, where $\pi_{i}^{r}=p_{i} L_{i}(\vec{p})+p_{i} E\left[\operatorname{Min}\left(D_{i}^{s}, \lambda y_{i}\right)\right]-w_{i}\left(L_{i}(\vec{p})+y_{i}\right)+b_{i} E\left[\left(\lambda y_{i}-D_{i}^{s}\right)^{+}+\beta y_{i}\right]$. By merging similar items, we have

$$
\pi_{i}^{r}=\pi_{i}^{d}-w_{i} y_{i}+b_{i}(1-\alpha) y_{i}+\left(p_{i}-b_{i}\right) E\left[\operatorname{Min}\left(D_{i}^{s}, \lambda y_{i}\right)\right]
$$

where $\pi_{i}^{d}=\left(p_{i}-w_{i}\right) L_{i}(\vec{p})$.We also assume that retailers' strategy sets are compact: $\left\{\left(p_{i}, y_{i}\right): w_{i} \leq p_{i} \leq p_{i}^{\max }, 0 \leq y_{i} \leq y_{i}^{\max }\right\}$, where $p_{i}^{\max }$ and $y_{i}^{\max }$ are large enough numbers and never restrict the players (Cachon and Netessine 2004). It can be shown that the game with decisions ( $p_{i}$, $\left.\mathrm{y}_{\mathrm{i}}\right)$ is equivalent to the game with decisions $\left(\mathrm{p}_{\mathrm{i}}, \mathrm{Y}_{\mathrm{i}}\right)$.

2.1.2. The Supplier's Problem

In order to build long-term relationships with retailers and make sure that the products are delivered to the market efficiently, the supplier is intended to use a system optimal contract. So the supplier's goal is to maximize the total supply chain profitby making the decision on contract parameters such as wholesale price $\mathrm{w}_{\mathrm{i}}$ and buyback price $\mathrm{b}_{\mathrm{i}}$.

2.1.3. Results

According to Zhao's results, when the model meets the condition (A) $\partial^{2} \pi_{i}^{d} / \partial p_{i}{ }^{2}<0$, 
$\partial^{3} \pi_{i}^{d} / \partial p_{i}^{3} \leq 0$ and condition (B) The distribution of $D_{i}^{s}$ has an increasing failure rate, there exists a pure-strategy Nash equilibrium, and the best response of retailer $i$ is the unique solution of

$$
\begin{array}{r}
\partial \pi_{i}^{r} / \partial p_{i}=\left(p_{i}-w_{i}\right) L_{i}^{(i)}(\vec{p})+L_{i}(\vec{p})+E\left[\operatorname{Min}\left(D_{i}^{s}, \lambda y_{i}\right)\right]=0 \\
\partial \pi_{i}^{r} / \partial y_{i}=-w_{i}+b_{i}(1-\alpha)+\left(p_{i}-b_{i}\right) \lambda \operatorname{Pr}\left(D_{i}^{s}>\lambda y_{i}\right)=0
\end{array}
$$

Without RFID technology, we only use the buyback contract to coordinate the supply chain. The key question is: in a decentralized supply chain with both price and inventory competition between independent retailers who face the same level of inventory inaccuracy, how should the supplier set parameters of the contract to achieve system optimal prices and safety stocks as an equilibrium and maximize the whole supply chain profit?

In an integrated supply chain, the supplier owns all retailers. The whole supply chain profit is:

$$
\pi^{c}=\sum_{i}\left\{p_{i} L_{i}(\vec{p})-c_{i}\left(L_{i}(\vec{p})+y_{i}\right)+p_{i} E\left[\operatorname{Min}\left(D_{i}^{s}, \lambda y_{i}\right)\right]\right\}
$$

where $\pi_{i}^{s}=\left(w_{i}-c_{i}\right)\left(L_{i}(\vec{p})+y_{i}\right)-b_{i}\left\{(1-\alpha) y_{i}-E\left[\operatorname{Min}\left(D_{i}^{s}, \lambda y_{i}\right)\right]\right\}$ and $c_{i}$ is the production cost of product i.

The global optimal solution of $\pi^{\mathrm{c}}$ meets Eq. (5) and Eq. (6) as following:

$$
\begin{aligned}
& \partial \pi^{c} / \partial p_{i}=\left(p_{i}-c_{i}\right) L_{i}^{(i)}(\vec{p})+L_{i}(\vec{p})+E\left[\operatorname{Min}\left(D_{i}^{s}, \lambda y_{i}\right)\right]+\sum_{j \neq i}\left(p_{j}-c_{j}\right) L_{j}^{(i)}(\vec{p})=0 \\
& \partial \pi^{c} / \partial y_{i}=-c_{i}+p_{i} \lambda \operatorname{Pr}\left(D_{i}^{s}>\lambda y_{i}\right)-\sum_{j \neq i} \lambda p_{j} \gamma_{i j} \operatorname{Pr}\left(D_{j}^{s}<\lambda y_{j}, \varepsilon_{i}>\lambda y_{i}\right)=0
\end{aligned}
$$

To fully coordinate retailers, the supplier should design the contract which lets Eq. (2) equal to Eq. (3) and Eq. (5) equal to Eq. (6).

Theorem 1. (The Nash Equilibrium without RFID) There exists a unique $\left(w_{i}^{*}, b_{i}^{*}\right)$ with $b_{i}^{*} \leq w_{i}^{*}<p_{i}^{c}$ and $w_{i}^{*} \geq c_{i}$, that perfectly coordinates the supply chain, namely $\left(\vec{p}^{c}, \vec{y}^{c}\right)$ is an equilibrium of the retailer game, as well as a Pareto-dominant equilibrium of the supplier-retailer game, where

$$
\begin{aligned}
& w_{i}^{*}=c_{i}-\sum_{j \neq i}\left(p_{j}^{c}-c_{j}\right) L_{j}^{(i)}\left(\vec{p}^{c}\right) / L_{i}^{(i)}\left(\vec{p}^{c}\right) \\
& b_{i}^{*}=\left[w_{i}^{*}-p_{i}^{c} \lambda \operatorname{Pr}\left(D_{i}^{s}>\lambda y_{i}^{c}\right)\right] /\left[(1-\alpha)-\lambda \operatorname{Pr}\left(D_{i}^{s}>\lambda y_{i}^{c}\right)\right]
\end{aligned}
$$

\subsection{The General Model with RFID technology}

\subsubsection{Basic Assumptions}

With RFID technology, retailers will no longer be troubled with inventory inaccuracy, i.e. $\alpha=0$ and $\beta=0$, so the inventory can be used to sale is $L_{i}(\vec{p})+y_{i}$. The tag cost per product is $c_{\mathrm{t}}$ which is paid by the supplier in order to reduce the whole unsatisfied demands.

The profit of retailer $\mathrm{i}$ is

$$
\pi_{i \text { RFID }}^{r}=\pi_{i}^{d}-\left(w_{i}-b_{i}\right) y_{i}+\left(p_{i}-b_{i}\right) E\left[\operatorname{Min}\left(D_{i}^{s}, y_{i}\right)\right]
$$

The whole supply chain profit is

$$
\pi_{R F I D}^{c}=\sum_{i}\left\{p_{i} L_{i}(\vec{p})-\left(c_{i}+c_{t}\right)\left(L_{i}(\vec{p})+y_{i}\right)+p_{i} E\left[\operatorname{Min}\left(D_{i}^{s}, y_{i}\right)\right]\right\}
$$

where $\pi_{i R F I D}^{s}=\left(w_{i}-c_{i}-c_{t}\right)\left(L_{i}(\vec{p})+y_{i}\right)-b_{i}\left\{y_{i}-E\left[\operatorname{Min}\left(D_{i}^{s}, y_{i}\right)\right]\right\}$.

\subsubsection{Results}

Theorem 2. (The Nash Equilibrium with RFID) After applying RFID technology, there exists a unique $\left(w_{i R F I D}^{*}, b_{i R F I D}^{*}\right)$ with $b_{i R F I D}^{*} \leq w_{i R F I D}^{*}<p_{i R F I D}^{c}$ and $w_{i R F I D}^{*} \geq c_{i}+c_{t}$, that perfectly coordinates the supply chain, namely $\left(\vec{p}_{R F I D}^{c}, \vec{y}_{R F I D}^{c}\right)$ is an equilibrium of the retailer game, as well as a Pareto-dominant equilibrium of the supplier-retailer game, where

$$
\begin{array}{r}
w_{i \text { RFID }}^{*}=c_{i}+c_{t}-\sum_{j \neq i}\left(p_{j}^{c}-c_{j}-c_{t}\right) L_{j}^{(i)}\left(\vec{p}_{R F I D}^{c}\right) / L_{i}^{(i)}\left(\vec{p}_{R F I D}^{c}\right) \\
b_{i \text { RFID }}^{*}=\left[w_{i \text { RFID }}^{*}-p_{i \text { RFID }}^{c} \operatorname{Pr}\left(D_{i}^{s}>y_{i \text { RFID }}^{c}\right)\right] / \operatorname{Pr}\left(D_{i}^{s}<y_{i \text { RFID }}^{c}\right)
\end{array}
$$




\section{Numerical Results}

In this section, we conduct numerical experiments to understand how the inventory inaccuracy influences the performance of the supplier. We consider how wholesale price and buyback pricechange as $\alpha$ and $\beta$ change, as well as howthe supplier's profits change before and after applying RFID. Before presentation of the results, we describe the test environment in detail.

\subsection{Test Environment}

We consider a supply chain consists of a supplier and two retailers who compete in both price and inventory. The deterministic portion of demand has a linear form, i.e. $L_{i}(\vec{p})=h-(k+\theta) p_{i}+\sum_{j \neq i} \theta\left(p_{j}-p_{i}\right)$. The uncertain demand is drawn from the uniform distribution, Uniform $[0,100]$. We let $\mathrm{h}=200, \mathrm{k}=12, \theta=5, \mathrm{c}=6$ and $\mathrm{c}_{\mathrm{t}}=0.1$.

\subsection{The Influence of Inventory Inaccuracy}
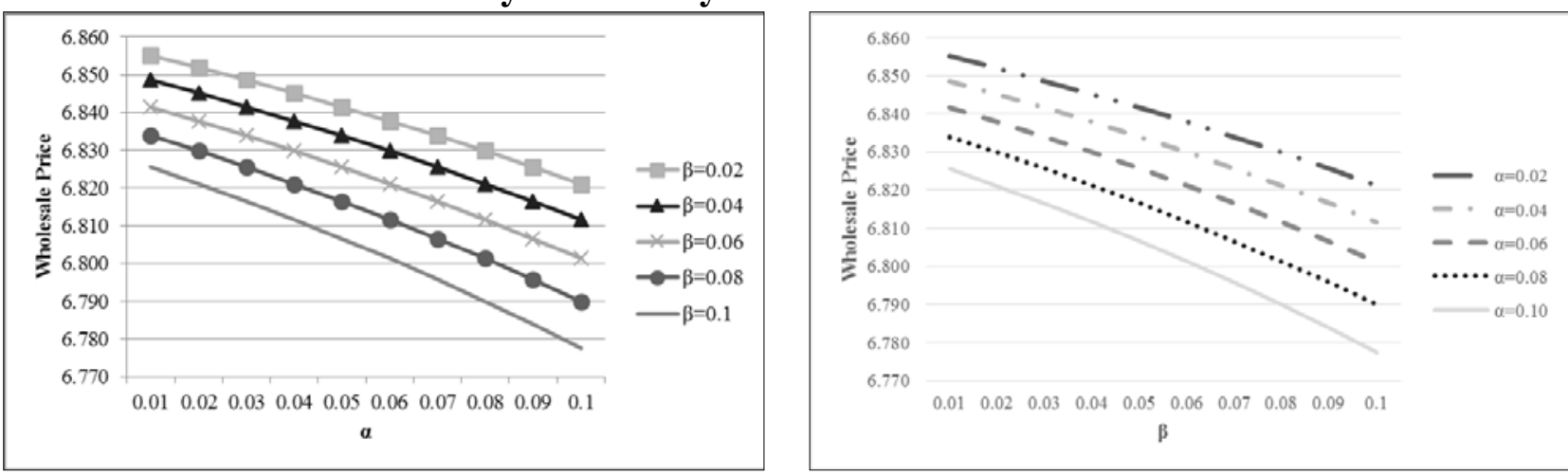

Fig.1. The impacts of $\alpha, \beta$ on the wholesale price
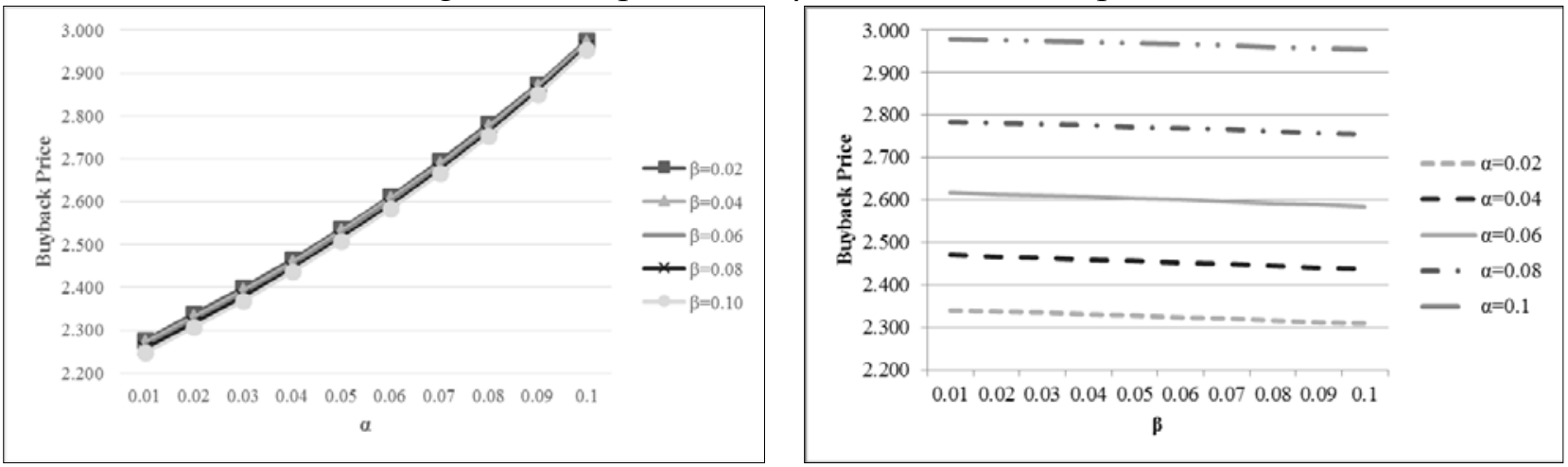

Fig.2. The impacts of $\alpha, \beta$ on the buyback price

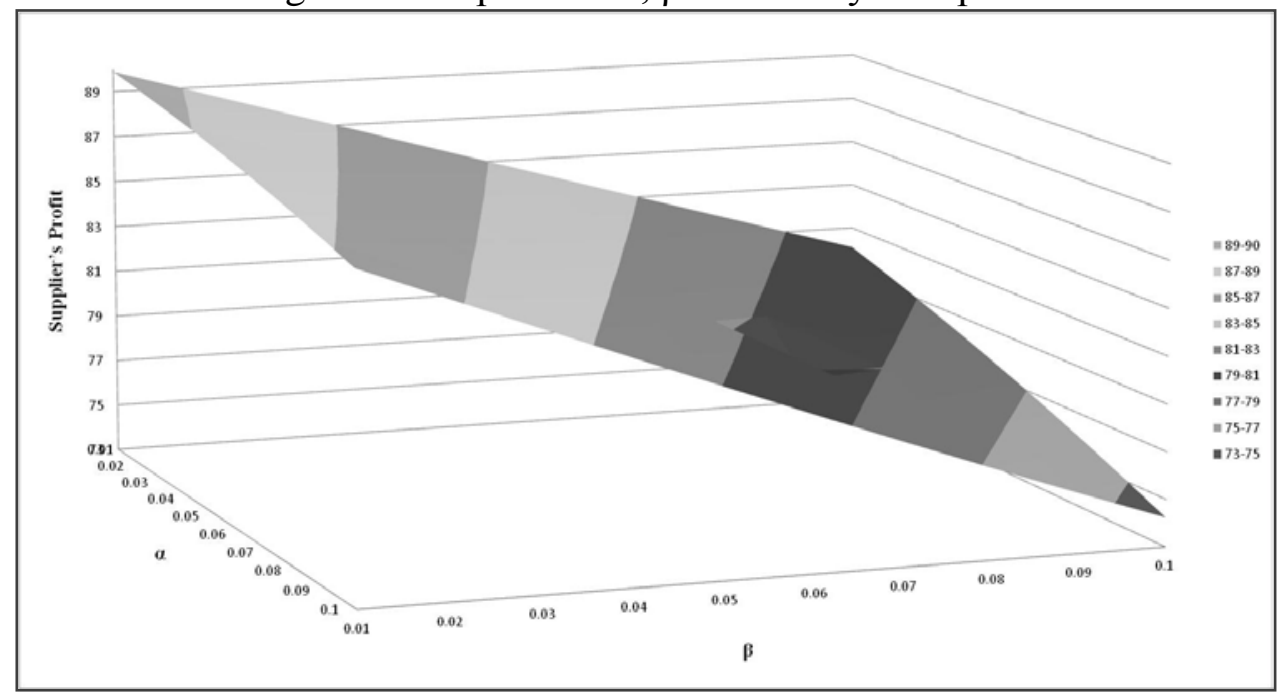

Fig.3. The impacts of $\alpha, \beta$ on the supplier's profit 
Based on Figure 1-3, we can draw the conclusions as following:

(i) As inventory inaccuracy increases, the wholesale price decreases.

The wholesale price $\mathrm{w}_{\mathrm{i}}$ is influenced by the equilibrium retail price $p_{i}^{*}$, which is impacted by $\alpha$ and $\beta$. When there is a higher level of inventory inaccuracy, the retailer set a lower safety stock, so the supplier will set lower wholesale prices to make retailers to order more.

(ii) As shrinkage rate $\alpha$ increases or misplacement rate $\beta$ decreases, the buyback price increases.

Because there exists inventory shrinkage, the retailer set a lower safety stock, and the supplier will set a higher buyback price to encourage more ordering. When there is a lower level of inventory misplacement, products that need to be repurchased are less, so the supplier will set a lower buyback price.

(iii) As inventory inaccuracy increases, the supplier's profit decreases.

Due to the existence of inventory inaccuracy, part of customers' demands cannot be satisfied so that the profit reduced.

3.3. The Influence of RFID Technology

In order to know the influence on the profit before and after applying RFID technology, we define the level of the supplier's profit improvement as $\left(\pi_{R F I D}^{s}-\pi^{s}\right) / \pi^{s} \times 100 \%$. After adopting RFID, the whole supply chain profits $\pi^{\mathrm{s}}$ is 87.9.

Table 1. The level of the supplier's profit improvement before and after using RFID (\%)

\begin{tabular}{|c|c|c|c|c|c|c|c|c|c|c|}
\hline$\beta \alpha$ & 0.01 & 0.02 & 0.03 & 0.04 & 0.05 & 0.06 & 0.07 & 0.08 & 0.09 & 0.10 \\
\hline 0.01 & -2.23 & -1.95 & -1.65 & -1.32 & -0.95 & -0.56 & -0.13 & 0.33 & 0.83 & 1.38 \\
\hline 0.02 & -1.03 & -0.70 & -0.35 & 0.03 & 0.45 & 0.90 & 1.38 & 1.91 & 2.48 & 3.10 \\
\hline 0.03 & 0.21 & 0.58 & 0.98 & 1.41 & 1.88 & 2.39 & 2.94 & 3.53 & 4.18 & 4.87 \\
\hline 0.04 & 1.47 & 1.89 & 2.34 & 2.83 & 3.36 & 3.92 & 4.54 & 5.20 & 5.92 & 6.69 \\
\hline 0.05 & 2.77 & 3.23 & 3.74 & 4.28 & 4.87 & 5.50 & 6.18 & 6.91 & 7.70 & 8.55 \\
\hline 0.06 & 4.09 & 4.61 & 5.17 & 5.77 & 6.41 & 7.11 & 7.85 & 8.66 & 9.52 & 10.45 \\
\hline 0.07 & 5.45 & 6.02 & 6.63 & 7.29 & 7.99 & 8.75 & 11.05 & 10.44 & 11.38 & 12.39 \\
\hline 0.08 & 6.84 & 7.46 & 8.13 & 8.84 & 9.61 & 10.43 & 11.31 & 12.26 & 13.27 & 14.36 \\
\hline 0.09 & 8.26 & 8.93 & 9.65 & 10.43 & 11.25 & 12.14 & 13.09 & 14.11 & 15.19 & 16.36 \\
\hline 0.10 & 9.70 & 10.43 & 11.21 & 12.04 & 12.93 & 13.88 & 14.89 & 15.98 & 17.13 & 18.37 \\
\hline
\end{tabular}

From the above table, we can observe that:

(i) When $\alpha=\beta=0.10$, before and after adopting RFID, the supplier's profits $\pi^{\mathrm{s}}$ are 89.9 and 87.9 respectively, and the level of its improvement is $-2.23 \%$. Thus, we can know that when the inventory shrinkage and misplacement rates are small, the cost with RFID is slightly higher than that without RFID. The advantages of RFID technology is not so obvious that the supplier prefers not to use RFID.

(ii) As $\alpha$ and Bincrease, the level of the supplier's profit improvement getting larger. In these cases, applying RFID can effectively prevent the inventory shrinkage and misplacement, so the cost before applying RFID is higher than that after applying RFID. It is worth noting that when $\alpha=0.01$, the level of the supplier's profit improvement is not positive until $\beta=0.08$, which reveals that the supplier becomes more likely to use RFID when the inventory misplacement is serious.

\section{Conclusion}

In this paper, we study the influence of the inventory inaccuracy in a traditional supply chain that consists of a single supplier and multiple retailers. We consider a supply chain with shrinkage and misplacement errors, consisting of one supplier and many retailers who are engaged in both price and inventory competition. We use the buyback contract to coordinate the supply chain, and apply RFID to improve its performance. Our results further enrich studies of the inventory inaccuracy, which can provide useful guidelines to supply chain firms.

For future research, we may extend the model with other contracts, such as revenue sharing contract and flexible commitment contract. Also, we can consider the situation that every retailer 
face different level of the inventory inaccuracy, which is more realistic.

\section{Acknowledgement}

This work was supported by the National Science Foundation of China Grant No. 71171022 andthe Grain Welfare Industry Research Projects of China (Grant No. 201313009-08).

\section{References}

[1] Hollinger, R.C., Adams, A. 2009 National Retail Security Survey Final Report. Report, 2010, University of Florida.

[2] A. Raman, N. DeHoratius, Z. Ton. Execution: The missing link in retail operations. California Management Review, 43 (3). 2001: 136-152.

[3] Fan T, Tao F, Deng S, et al. Impact of RFID technology on supply chain decisions with inventory inaccuracies [J]. International Journal of Production Economics, 2015, 159: 117-125.

[4] Rekik Y, Syntetos A, Jemai Z. An e-Retailing Supply Chain Subject to Inventory Inaccuracies [J]. International Journal of Production Economics, 2015.

[5]Zhao X. Coordinating a supply chain system with retailers under both price and inventory competition. Production and Operations Management. 17(5). 2008,9-10: 532-542.

[6] Cachon G P, Netessine S. Game theory in supply chain analysis [M]. Handbook of Quantitative Supply Chain Analysis. Springer US, 2004: 13-65. 